\title{
Quality audit of an office-based "fast track" elective ankle ligament repair program
}

\author{
by Ingrid Ekenman, $\mathrm{MD}, \mathrm{PhD}^{1}$, Metha Brattwall, $\mathrm{MD}^{2}$, Ibrahim Turan, $\mathrm{MD}, \mathrm{PhD}^{3}$, \\ Jan Jakobsson, $\mathrm{MD}, \mathrm{PhD}^{4}$
}

The Foot and Ankle Online Journal 2 (3): 4

Background: The transition from in-hospital care to day surgery and further to office-based fast-track surgery is increasing. This study is an audit of 50 consecutive patients undergoing elective ankle ligament repair following our fast-track/short-stay office-based protocol.

Methods: All patients were provided oral and written instruction prior to surgery and a cast was also prepared in advance. A strict program was followed during the day of surgery. Fifty, 20 male and 30 female, ASA 1-2 patients mean age 43 years (18-64), weight 80 (52 - 112) kg, undergoing elective ankle ligament repair under general anaesthesia were followed per strict office-based program. Mean duration of surgery and time to discharge was 19 (13-37) and 56 (35-75) minutes respectively.

Results: All patients had an uncomplicated course; no complications or readmissions were seen. Pain ratings were below our internally set quality goals, two patients (4\%) reported severe pain after discharge, during the afternoon following surgery, one in the evening the day of surgery and one the first postoperative morning. Female experienced overall more postoperative pain although a higher initial loading dose of oral analgesics. Overall patients' satisfaction was high; all patients rated care and postoperative course as adequately satisfactory.

Conclusion: Office-based fast-track/short stay is seemingly feasible when a strict program is followed.

Keywords: Office-based surgery, fast track, postoperative pain; PONV

\section{The proportion of surgery performed on a day care basis is increasing and this trend is expected to continue. ${ }^{1}$}

This is an Open Access article distributed under the terms of the Creative Commons Attribution License. It permits unrestricted use, distribution, and reproduction in any medium, provided the original work is properly cited. @The Foot and Ankle Online Journal (www.faoj.org)

\footnotetext{
Address correspondence to: Jan Jakobsson, MD, PhD, Associate Prof Foot \& Ankle Surgical Centre

Storängsvägen 10

11452 Stockholm

SWEDEN

Jan.jakobsson@ki.se

${ }^{1}$ Karolinska Institutet, Institution for CLINTEC, Foot \& Ankle Surgical Center, Stockholm, Sweden.

2 Sahlgrenska Academy, University Hospital Möndal, Department of

Anaesthesia, Gothenburg, Sweden.

${ }^{3}$ Foot \& Ankle Surgical Center Stockholm Sweden.

${ }^{4}$ Associate Professor, Karolinska Institutet, Institution for Physiology \&

Pharmacology Department of Anaesthesia \& Intensive Care, Foot \& Ankle

Surgical Center, Stockholm, Sweden.
}

Dedicated procedure specific programs are being developed in order to improve the overall handling of day case procedures. Pain is one of major limiting factors for successful conversion to short stay surgery. ${ }^{2,3}$ Ankle ligament repair has been identified as one of the procedures causing most pain at 24 hours. ${ }^{4}$

Follow-up of day case surgery is of strict importance to secure both safety and quality of care. ${ }^{5}$ Internal quality goals should be set and audited in order to secure adequate quality. We have set up goals of 90 percent patient satisfaction and that no more than 20 percent of patients should experience painor severe pain during the early postoperative course. 
We have during 2007 developed an office based fasttrack program for elective ankle ligament repair.

The aim of the present follow-up audit was to see at what extent our internal quality goals were met following the introduction of the fast-track officebased ankle ligament repair program.

\section{Methods}

We followed during the period of March through August 2008 we followed the perioperative and first 24 hour postoperative course of 50 consecutive patients with informed consent undergoing elective ankle ligament repair made according to our newly implemented office based fast track program.

All patients were seen preoperatively by the orthopaedist at our outpatient clinic. They were during the initial visit examined and informed by the surgeon about the procedure, provided prescriptions of routine pain medication and instructions about pain management and rehabilitation following surgery. They were instructed to refrain from food for 6 hours prior to surgery but allowed to drink limited amounts of clear liquids up to 2 hours prior to surgery.

When arriving in the day surgical center they were directly guided to the surgical unit to prepare for surgery. All patients walked into the OR following a brief preoperative interview by the attending anaesthetists (JJn). All patients had an intravenous (IV) line, balanced glucose infusion was started and 8 mg betamethasone was immediately given IV. Washing and dressing was done with the patient awake and sedated with a small dose of alfentanil/propfol IV. All patients had general anaesthesia; induction with sleep dose propofol and a bolus of alfentanil. A disposable laryngeal mask airway was inserted immediately after induction. All patients were breathing spontaneous. Anaesthesia was provided with sevoflurane in a circle system, depth of anaesthesia adjusted on clinical signs and aiming at a Cerebral State Index of 50 plus minus 5 during surgery (Cerebral State Monitor, Danmeter AS, Odense, Denmark).
Sevoflurane was discontinued during suturing aiming for a CSI of $60-70$. Before suturing 8-10 cc of bupivacaine $5 \mathrm{mg} / \mathrm{ml}$ was infiltrated into the surgical site soft tissue. Surgery was standardized and performed by one surgeon. The wound was dressed with a soft dressing. A Cast boot (Air-cast, DJO LCC, CA, USA) was attached for stabilization, no cast was applied, and the patients were allowed to walk directly after surgery.

Ready for discharge was evaluated by a basic scoring system; (1) fully awake and orientated, (2) able to drink, (3) stand and walk unaided, (4) no or mild pain less than 4 and (5) no or minor nausea. All patients should have a relative of friend as escort for journey back home.

At wound close all patients had bupivacaine $5 \mathrm{mg} / \mathrm{ml}$ in the surgical field soft tissue $8-10 \mathrm{cc}$. The cast boot was put on before moving from the operating table. Paracetamol and etoricoxib $120 \mathrm{mg}$ oral was given at arrival in the step-down unit. All patients were provided paracetamol $1 \mathrm{gr}$ to take 1 - 4 times day of surgery and dextropropoxyphene $100 \mathrm{mg}$ as rescue analgesia. Further pain medication was based on a combination of NSAID and paracetamol for 6 days as needed.

\section{Results}

\section{Demographics}

Fifty consecutive patients, 20 male and 30 female with an ASA 1-2, patients mean age 43 years (18-64), weight $80(52-112) \mathrm{kg}$, undergoing elective officebased fast-track ankle ligament repair under general anaesthesia were followed and evaluated.

\section{Perioperative observations}

The mean duration of surgery and time of discharge was 19 (13-37) and 56 (35-75) minutes respectively. All patients were fast-tracked; walking escorted to the step-down unit by-passing the recovery room and all 50 patients were discharge eligible within 75 minutes. 


\begin{tabular}{|c|c|c|c|}
\hline & $\begin{array}{c}\text { Male } \\
(n=20)\end{array}$ & $\begin{array}{c}\text { Female } \\
(n=30)\end{array}$ & $\begin{array}{c}\text { All } \\
(n=50)\end{array}$ \\
\hline Age (years) & $41 \pm 11$ & $44 \pm 13$ & $43 \pm 13$ \\
\hline Weight (kg) & $90 \pm 12$ & $74 \pm 14 * * *$ & $80 \pm 15$ \\
\hline Duration of surgery (min.) & $19 \pm 4$ & $19 \pm 5$ & $19 \pm 4$ \\
\hline Propofol/kg (mg) & $2.4 \pm 0.4$ & $2.6 \pm 0.4$ & $2.5 \pm 0.4$ \\
\hline Alfentanil/kg $(\mu \mathrm{g} / \mathrm{kg})$ & $0.94 \pm 0.06$ & $0.95 \pm 0.1$ & $0.94 \pm 0.1$ \\
\hline Mean Etaa (sevoflurane \%) & $1.03 \pm 0.2$ & $1.05 \pm 0.3$ & $1.04 \pm 0.3$ \\
\hline Mean CSI & $46 \pm 6$ & $46 \pm 4$ & $46 \pm 5$ \\
\hline Paracetamol/kg (mg) & $23 \pm 3$ & $25 \pm 3 *$ & $24 \pm 3$ \\
\hline Etoricoxib (mg/kg) & $1.4 \pm 0.2$ & $1.7 \pm 0.3 * * *$ & $1.6 \pm 0.3$ \\
\hline Analgesics before discharge & $2(10 \%)$ & $5(17 \%)$ & $7(14 \%)$ \\
\hline Discharge (min.) & $57 \pm 8$ & $55 \pm 7$ & $55 \pm 8$ \\
\hline
\end{tabular}

Table 1 Demographics and perioperative observations (mean \pm standard deviation). Etaa : endtidal anaesthetic agent, CSI: Cerebral State Index, $* \mathrm{P}<0.05$ paracetamol mg/kg males vs. females ANOVA, $* * * \mathrm{P}<0.001 \mathrm{Wieght}(\mathrm{kg})$ and etoricoxib $\mathrm{mg} / \mathrm{kg}$ males vs. females ANOVA.

In all, 7 patients were provided rescue analgesics while still in the hospital. No complications were recorded under or following surgery. Demographics and perioperative observations are presented in table 1.

The average patient turnover included arrival to the preoperative holding area at 08.00. The start of surgery was at 08.15 with end surgery at 08.40. Discharge criteria was fulfilled at 9.50- 10.00, and discharged within 150 minutes from the arrival in the unit at 10.30 .

\section{Follow up after discharge}

Pain was overall mild. Twelve patients reported pain and five had severe pain at one occasion $(10 \%)$ when looking at the entire first 24 hour postoperative period. Females and especially females that had experienced pain before discharge were most likely to report postoperative pain. Among the 5 female patients that experienced pain before discharge, 2 patients $(40 \%)$ rated pain as severe on at least one occasion during the 24 hour follow-up period as compared with 2 out of 25 females (8\%) that had not experienced pain before leaving the hospital. Twelve patients 4 males and 8 females consumed in all 25 rescues opioid tablets ( 7 and 18 tablets for male and female respectively).
Eight patients reported brief episodes of emesis after discharge and sleep was perceived as good or only minor disturbed in 44 out of the 50 patients studied. Patients with pain and need for rescue opioids had double the incidence of PONV as compared to the patients not experiencing pain and without intake of rescue opioid $31 \%$ and $14 \%$ respectively. Patients' satisfaction was high; all 50 patients reported being satisfied with the overall perioperative course. Postopertive observations are presented in table 2.

\section{Discussion}

We found our fast-track/short-stay office-based ligament repair program being feasible and associated to high patients' satisfaction fulfilling our internally set quality goals.

All patients had general anaesthesia but no muscle relaxation. Depth of anaesthesia was administered based on clinical signs and the use of the Cerebral State Monitor providing an EEG derived index of the anaesthetic state. 6 The value of EEG-monitoring in reducing awareness with recall has recently been challenged by Avidan, et al. ${ }^{7}$ 


\begin{tabular}{|l|c|c|c|}
\hline & $\begin{array}{c}\text { Male } \\
(\mathrm{n}=20)\end{array}$ & $\begin{array}{c}\text { Female } \\
(\mathrm{n}=30)\end{array}$ & $\begin{array}{c}\text { All } \\
(\mathrm{n}=50)\end{array}$ \\
\hline $\begin{array}{l}\text { No or mild/Pain/severe pain; } \\
\text { Afternoon day of surgery }\end{array}$ & $\mathbf{9 5 / 5 / 0}$ & $\mathbf{7 0 / 2 3 / 7} *$ & $80 / 16 / 4$ \\
\hline Evening day of surgery & $\mathbf{9 0 / 1 0 / 0}$ & $\mathbf{6 4 / 3 3 / 3}$ & $64 / 24 / 2$ \\
\hline Morning day after surgery & $\mathbf{1 6 / 5}$ & $\mathbf{3 0 / 3}$ & $24 / 4$ \\
\hline Opioid rescue & $\mathbf{8 0 / 2 0}$ & $\mathbf{7 3 / 2 7}$ & $76 / 24$ \\
\hline No emesis/Emesis postoperatively & $\mathbf{9 5 / 5}$ & $\mathbf{7 6 / 2 4}$ & $84 / 16$ \\
\hline $\begin{array}{l}\text { No or minor sleep disturbance/ } \\
\begin{array}{l}\text { Disturbed sleep first } \\
\text { Postoperative night }\end{array}\end{array}$ & $\mathbf{9 5 / 5}$ & $\mathbf{8 3 / 1 7}$ & $88 / 12$ \\
\hline $\begin{array}{l}\text { Patients' satisfaction; } \\
\text { Adequate/Inadequate }\end{array}$ & & & 100 \\
\hline
\end{tabular}

Table 2 Postoperative, follow-up observations percent of patients.

$* \mathrm{P}<0.05$ Chi-Square test

The positive effects in better titrating depth of anaesthesia has however been shown in a metaanalysis explicitly looking at ambulatory anaesthesia. ${ }^{8}$

It should indeed be acknowledged that our patients received a multi-modal analgesic regime and balanced anaesthesia in accordance to recent recommendations. ${ }^{9} \quad$ All patients received both betamethasone and alfentanil at induction. Romunstad, et al., has also convincingly shown the analgesic properties postoperatively of steroids ${ }^{10}$, improving not only pain but also overall patient satisfaction. The results should also take into account that all patients had local anaesthesia (bupivacaine) at wound closure and a loading dose of both etoricoxib $120 \mathrm{mg}$ (regardless of weight) and paracetamol 30 $\mathrm{mg} / \mathrm{kg}$ orally at arrival in the phase II recovery area. The profound analgesic and opioid sparing effects from coxibs in orthopaedic surgery has been shown repeatedly, reducing pain as well as the need for opioid rescue analgesics. ${ }^{11-13}$

All patients were already provided during the perioperative outpatient office visit with information about postoperative training and pain management.
Analgesics for the first postoperative 24 hours were given to each patient in pre-prepared packages at time of discharge. It should also be acknowledged that only one orthopaedic surgeon with more than 20 years experience in foot surgery performed all the surgery and that all the staff had several years of daysurgical experience.

Our overall results were satisfactory in our view. Looking at internal department specific quality goals; that not more than $5 \%$ of patients should experience severe pain, not more than $10 \%$ of patients should have any negative comments about satisfaction and that less than $20 \%$ should experience nausea: All three are fulfilled. ${ }^{14}$ Our quality goals are similar to what others have chosen. ${ }^{15}$ When looking for factors associated with more pronounced pain female gender and early, pre-discharge experience of pain were variables found associated with more intense postoperative pain. Intraoperatively no differences between males and females were noticed. Females had in general a lower body weight and as a consequence of fixed dosing, female patients had a higher loading dose of both etoricoxib and paracetamol. 
Still, the pain was more frequently reported among female patients. The use of rescue opioid analgesics was also somewhat more common among female patients. Females that required a need for rescue pain medication before leaving the hospital were associated with the highest risk for pain and rescue opioid consumption during the first 24 hours after surgery. Also PONV was not surprisingly seen in higher frequency among females with a need for rescue analgesics. Patients' satisfaction was overall rated as high. Many patients made explicit comments around the quality of care, comments such as; rapid and efficacious, professional team etc.

\section{Conclusion}

Although entire duration of the hospital visit was less than 3 hours no complications, return to hospital or other complaints were found. Patient selection, optimising logistics and structured postoperative pain management program is of importance for success. An office based fast-tracking/short-stay program for patients undergoing elective ankle ligament repair seems feasible and associated with high patient satisfaction. Careful patient selection, preoperative information including information about pain medication, rehabilitation and optimised perioperative logistics should be acknowledged.

\section{References}

1. Segerdahl M, Warrén Stomberg M, Rawal N, Brattwall, M, Jakobsson J. Clinical practice and routines for day surgery in Sweden: results from a nation-wide survey. Acta Anaesthesiol Scand 52: 117 - 24, 2008.

2. Beauregard L, Pomp A, Choinière M. Severity and impact of pain after day-surgery. Can J Anaesth 45: 304 - 11, 1998.

3. Horvath KJ. Postoperative recovery at home after ambulatory gynecologic laparoscopic surgery. J Perianesth Nurs 18 (5): $324-$ 34, 2003.

4. McGrath B, Elgendy H, Chung F, Kamming D, Curti B, King S. Thirty percent of patients have moderate to severe pain $24 \mathrm{hr}$ after ambulatory surgery: a survey of 5,703 patients. Can J Anaesth 51: 886 - 91, 2004.
5. Kavanagh T, Hu P, Minogue S. Daycase laparoscopic cholecystectomy: a prospective study of post-discharge pain, analgesic and antiemetic requirements. Ir J Med Sci 177: 111 - 5, 2008.

6. Anderson RE, Jakobsson JG. Cerebral state monitor, a new small handheld EEG monitor for determining depth of anaesthesia: a clinical comparison with the bispectral index during day-surgery. Eur J Anaesthesiol 23: 208 - 12, 2006. 7. Avidan MS, Zhang L, Burnside BA, Finkel KJ, Searleman AC, Selvidge JA, Saager L, Turner MS, Rao S, Bottros M, Hantler C, Jacobsohn E, Evers AS.Anesthesia awareness and the bispectral index. N Engl J Med 358 (11):1097 - 108, 2008.

8. Liu SS. Effects of Bispectral Index monitoring on ambulatory anesthesia: a meta-analysis of randomized controlled trials and a cost

analysis. Anesthesiology 101: 311 - 5, 2004.

9. Myles PS, Power I. Clinical update: postoperative analgesia. Lancet 2007, 10; 810 - 2, 2007.

10. Romundstad L, Breivik H, Roald H, Skolleborg K, Haugen T, Narum J, Stubhaug A. Methylprednisolone reduces pain, emesis, and fatigue after breast augmentation surgery: a singledose, randomized, parallel-group study with methylprednisolone $125 \mathrm{mg}$, parecoxib $40 \mathrm{mg}$, and placebo. Anesth Analg. 102: $418-$ 25, 2006.

11. Reuben SS, Ekman EF, Charron D. Evaluating the analgesic efficacy of administering celecoxib as a component of multimodal analgesia for outpatient anterior cruciate ligament reconstruction surgery. Anesth Analg. 105: 222 - 7, 2007. 12. Reuben SS, Buvenandran A, Katz B, Kroin JS. A prospective randomized trial on the role of perioperative celecoxib administration for total knee arthroplasty: improving clinical outcomes. Anesth Analg 106: 1258 - 64, 2008. 13. Toivonen J, Pitko VM, Rosenberg PH. Etoricoxib premedication combined with intra-operative subacromial block for pain after arthroscopic acromioplasty.Acta Anaesthesiol Scand. 2007; 51: 316-21.

14. Turan I, Assareh H, Rolf Ch, Jakobsson J. Etirocoxib, paracetamol, and dextropropoxyphene for postopereative pain management: A quiestionaire survey of consumption of takehome medication after elective hallux valgus surgery. Foot Ankle Spec 1: $88-92,2008$.

15. Ismail S, Hussain AM. Adequacy of postoperative pain relief after discharge. J Pak Med Assoc 57: 371 - 3, 2007. 